\title{
ÁLBUMES ILUSTRADOS Y DESARROLLO DE CIUDADANÍA DEMOCRÁTICA. UNA PROPUESTA PARA EDUCACIÓN PRIMARIA A PARTIR DE UN CASO PARADIGMÁTICO: ERIC, DE SHAUN TAN
}

Leonor Ruiz Guerrero

Sebastián Molina Puche

Universidad de Murcia

\begin{abstract}
RESUMEN: En este estudio se plantea cómo la literatura infantil y juvenil (LIJ) puede convertirse en una herramienta apropiada para que el alumnado de Educación Primaria avance en el desarrollo de una ciudadanía democrática. Dentro de la LIJ se ha abordado el género álbum ilustrado, siguiendo investigaciones previas, como las de Encabo, López y Jerez (2012), o las de los trabajos compilados por Johnston y Bainbridge (2013), entre otras. Se ha procurado, no obstante, superar las limitaciones de estos antecedentes. En el presente trabajo se ha incidido tanto en la mejora de las competencias sociales y cívicas como en un mayor conocimiento del género álbum. Se ha seleccionado para la lectura la obra Eric, de Shaun Tan. La propuesta se ha concretado con catorce participantes de cuarto a sexto curso de Educación Primaria. Se ha utilizado como método principal el grupo de discusión, además de un cuestionario.
\end{abstract}

PALABRAS CLAVE: Álbum ilustrado, ciudadanía, Educación Primaria, investigación participativa.

\section{PICTUREBOOKS AND DEVELOPMENT OF DEMOCRATIC CITIZENSHIP. A PROPOSAL FOR PRIMARY EDUCATION FROM A PARADIGMATIC CASE: ERIC, BY SHAUN TAN}

\footnotetext{
ABSTRACT: This study considers how the Children's Literature could be an appropriate tool so that the students of Primary Education progress in the development of democratic citizenship. Within the Children's Literature, the picturebook has been addressed, following previous studies such as those by Encabo, López and Jerez (2012), or the works compiled by Johnston and Bainbridge (2013), among others. It has been tried, however, to overcome the limitations of this background. In the present work, it has been stressed both
} 
the improvement of the social and civic competences and a greater knowledge of the genre. For the reading it has been selected the work Eric, by Shaun Tan. The proposal has been carried out with fourteen participants from the fourth to the sixth year of Primary Education. It has been employed the focus group as the main method, as well as a questionnaire.

KEYWORDS: Picturebook, citizenship, Primary Education, participatory research.

Recibido: 30/08/2016

Aceptado: 03/02/2017

Correspondencia: Leonor Ruiz Guerrero, Departamento de Didáctica de la Lengua y la Literatura, Facultad de Educación, Campus de Espinardo, Universidad de Murcia, 30100 Murcia. Email: Imruiz@um.es.

\section{INTRODUCCIÓN}

Son diversos los autores que han reflexionado a lo largo del tiempo sobre el papel que las narrativas tienen en la construcción tanto de las identidades culturales y sociales, como de los contextos en que tales identidades se insertan.

Dentro de este desempeño, la Literatura Infantil y Juvenil (LIJ) tiene una función destacada. Así, los investigadores que se han centrado en ella han concluido de forma mayoritaria que este tipo de literatura actúa a su vez como reflejo y como agente de esos contextos culturales y sociales. En otras palabras, se ha hecho evidente que los textos dirigidos al público infantil han sido empleados a lo largo de la historia para aproximar a este al statu quo imperante en cada momento. Tal y como exponen Pantaleo y Sipe: "Historically, children's literature has reflected social values, attitudes, and knowledge" (2012, p. 1).

No cabe duda que la LIJ se vislumbra como un recurso con un gran potencial en el ámbito educativo formal. Dentro de ella, nuestro interés se dirige hacia un género en particular, el álbum ilustrado. Género que surge precisamente al albor de los cambios sociales producidos a mediados del siglo XX, y que los refleja de forma particular. Por ello, nos parece propicio para alcanzar nuestro objetivo último, el desarrollo de contenidos vinculados a la ciudadanía democrática.

Precisemos un poco más el porqué de este potencial, así como los objetivos que se pretenden lograr. Las posibilidades del género parten de lo que expone certeramente Colomer (2010), al señalar que en la actualidad se aprecia un cambio en la naturaleza de los principios abarcados por los álbumes, con respecto a décadas precedentes. Si en los años sesenta y setenta del siglo XX la "democracia, igualdad de derechos, autonomía personal y capacidad de relación son valores muy extendidos en la producción de libros infantiles" (p. 61), en el momento actual destaca un "énfasis notable en la dedicación de las obras [...] a una educación en valores más complejos a nivel de la convivencia multicultural, en el plano social." (p. 58). 
Aunque con un enfoque más amplio, esta variación también es evidenciada por Bainbridge y Beverly (2013), apuntando en su caso hacia la conveniencia de que el futuro profesorado emplee los álbumes como recurso:

Because picture books are now designed for a wider age range of readers and broader reading purposes than in the past, it is important that preservice teachers consider the potential of picture books for inclusion in classroom activities across the grades. (p. 18).

En este sentido, con la propuesta que aquí se defiende se pretenden alcanzar los siguientes objetivos:

- Avanzar hacia el desarrollo de principios propios de una ciudadanía democrática (tolerancia, aceptación de la diversidad, diálogo como forma de resolución de conflictos, etc.) por parte del alumnado de Educación Primaria.

- Desestabilizar los estereotipos y esquemas previos del alumnado con respecto a la diversidad y al par identidad/alteridad.

- Iniciar al alumnado en el desarrollo del pensamiento crítico y la adopción de puntos de vista alternativos.

- Provocar la reflexión de los alumnos sobre la comunicación intercultural y las consecuencias de su ausencia.

- Aproximar a los discentes al género álbum y sus particularidades (textos abiertos; presencia de dos tipos de narración, verbal y visual, interconectados; ambigüedades, etc.)

Resulta conveniente indicar que, de entre esos objetivos, es especialmente relevante el referido al pensamiento crítico, pues, citando a Santisteban: "la educación y el pensamiento crítico son interdependientes en una sociedad democrática" (2004, p. 2).

El alcance del género álbum y su utilidad para los citados fines, ha sido abordado con anterioridad por otros equipos de investigación. Cabe mencionar las líneas abiertas por O’Neil (2010); Encabo, López y Jerez (2012); Johnston y Bainbridge (2013); Cotton (2000) o Cotton y Daly (2014). Sin embargo, se han percibido limitaciones en cuanto a las temáticas o los ámbitos de exploración en estos estudios, que pretenden superarse con el presente.

De forma más concreta, en este documento se ha propuesto el trabajo con un único álbum: Eric, de Shaun Tan. Se sugiere su aplicación en las aulas de Educación Primaria, haciendo uso del grupo de discusión como técnica principal, y considerando el enfoque sociocrítico.

\section{ReVISIÓN DE LA LITERATURA}

Se hace preciso comentar con más detenimiento los antecedentes investigadores que sustentan teóricamente nuestra propuesta.

Con respecto a $\mathrm{O}^{\prime} \mathrm{Neil}$ (2010), en su trabajo plantea la enseñanza de justicia social a través del empleo de álbumes postmodernos. De los tres ejes en torno a los que gira su obra, compartiremos dos: la consideración y el reconocimiento de puntos de vista alternativos, y la resistencia a los estereotipos.

Por su parte, la investigación de Encabo, López y Jerez (2012) se centra en el desarrollo de una educación intercultural en el ámbito europeo, a través del empleo de una selección de álbumes. Este estudio, por temática y recursos, se constituye en un pilar importante para nosotros. 
Johnston y Bainbridge (2013), asimismo, plantean en su compilación de trabajos cómo enfocar la cuestión de la diversidad a partir del uso de álbumes ilustrados. Su estudio cuenta como participantes con futuros docentes. La limitación la presenta el ceñirse al ámbito canadiense.

En lo que atañe a Cotton (2000), antecedente a su vez de la propuesta de López, Encabo y Jerez, en su obra analiza el potencial de los álbumes para ayudar al conocimiento de la identidad europea, y se centra también en la educación formal. Más tarde, su atención se desplaza al ámbito neozelandés, elaborando con Daily, en 2014, una investigación en la que atiende nuevas cuestiones. De entre ellas rescatamos los préstamos lingüísticos y los protocolos culturales, por enlazar con nuestra propuesta.

Por último, no podemos cerrar este apartado sin hacer referencia a la tesis de máster elaborada por Lebedeva (2013), dado que su trabajo se centra en la obra de Shaun Tan, autor seleccionado en este artículo. Según expone la investigadora, la incertidumbre que Tan muestra en sus álbumes, a través de un juego de ausencias/presencias, facilita que el público lector participe de forma singular en la construcción de los significados. Es decir, este autor se "ausenta" voluntariamente de sus textos, presentando finales abiertos y ambigüedades que obligan a quienes los leen a completarlos, comprometiendo su presencia en ellos. Todo esto hace que el estudio de Lebedeva se manifieste también como piedra angular para el nuestro.

Si bien este contexto investigador resulta fundamental, se aprecian en él algunas limitaciones. Con la presente propuesta se aspira a solventarlas aunque sea solo en parte.

\section{Álbum Seleccionado: ERIC, de Shaun TAN}

Aunque podemos señalar que no son pocos los álbumes que tratan las cuestiones que aquí se abordan. Baste echar una ojeada a cualquiera de los antecedentes señalados para recopilar unos cuantos títulos. Lo cierto es que la intención de superar las limitaciones de tales antecedentes nos conducía a buscar ejemplares alternativos. Se hacía preciso un texto que pudiese solventar las barreras de un contexto espacio-temporal concreto, de unos personajes claramente delimitados y reconocibles, de un argumento cerrado o iterativo... En este sentido, el álbum seleccionado lo hacía posible, de ahí la denominación de paradigmático. No obstante, veremos con más detenimiento a continuación los aspectos que han motivado esta elección.

La obra que aquí se propone, Eric, forma parte del libro Cuentos de la periferia, que es un álbum ilustrado compuesto de quince historias diferentes. Sin embargo, este título en concreto ha sido también publicado de manera independiente, en pequeño formato. Mas en este caso solo está disponible en inglés.

En este artículo vamos a analizar esta última edición, pues presenta ligeras variaciones con respecto a la editada en español que creemos interesante remarcar.

Por otro lado, Cotton y Daly (2014, p. 104) nos dan parte de la clave para comprender la elección de este álbum en particular, cuando comentan que "the power of picture books as mirrors in societies with diversity in both culture and language, [...], cannot be denied. These stories, however, can also provide windows into other cultures for children from many parts of the world". Así es, los álbumes poseen esta doble función, como espejos de la diversidad cultural propia, y al mismo tiempo como precursores 
del acceso a otras culturas. En Eric encontramos este rasgo, empero va un paso más allá, pues la reflexión que propicia abunda en el cómo el modo de concebir nuestra cultura puede convertirse en un obstáculo para entender otras y aceptar la diversidad. En esta obra vemos reflejados nuestros valores culturales, en el sentido de espejo que proponen Cotton y Daly (2014); pero también observamos el reflejo tamizado de una cultura que no nos es conocida. El filtro que se interpone es el que crea la perspectiva distanciadora que desestabiliza al público lector.

A estos argumentos que justifican la elección se unen otros dos. Uno es el de que esta obra, como ya se ha apuntado, supera las limitaciones de otras empleadas en otros estudios, ya que, en este caso, no hay una ubicación temporal ni espacial determinada, no hay una contextualización cultural ni lingüística concreta.

El segundo factor añadido es la apertura del texto, que lo diferencia de otros que tratan cuestiones similares (interculturalidad, encuentro de contextos diversos, etc.). Tan no cierra el sentido ni los significados, la ambigüedad impregna tanto las imágenes como la parte verbal. Se trata de la estrategia (ausencia/presencia) de la que nos había hablado Lebedeva (2013) en su tesis. Un recurso nada desdeñable, pues es precisamente a partir del mismo que puede surgir la reflexión que conduzca al desarrollo de una ciudadanía más democrática.

Finalmente, un último aspecto que ha determinado la elección, ha sido el hecho de que este álbum se aleja de las convenciones de los textos de temática similar. No hay un inmigrante que se siente alienado, ni un grupo humano que rechaza al diferente. Más bien somos espectadores de una situación en la que la identificación se presenta como conflictiva. En la que, en un primer momento, parece que se nos abre la vía para empatizar con quien acoge (por similitud cultural, quizás, o por el tipo de voz narrativa). Y sin embargo, conforme avanza el texto se nos aleja de ese personaje, que no es capaz de entender al otro, que está construyendo la otredad misma sin percatarse de ello. En cierto modo, podemos decir que Eric provoca que nuestra diferenciación entre identidad/alteridad se haga evidente y se ponga en jaque.

Finalmente, podemos verificar que, aún sin entrar en un análisis pormenorizado, Eric puede ser una opción idónea para encaminar al alumnado hacia la adquisición de principios democráticos en el ámbito educativo. Este álbum puede procurar el despliegue del pensamiento crítico, llevando al cuestionamiento de nuestras ideas previas sobre el encuentro intercultural (idealizado, o concebido como problemático). Puede, en última instancia, hacer viable la adquisición de las competencias sociales y cívicas presentes en el actual currículo de la Ley Orgánica para la Mejora de la Calidad Educativa (LOMCE): "Adquirir estas competencias supone ser capaz de ponerse en el lugar del otro, aceptar las diferencias, ser tolerante y respetar los valores, las creencias, las culturas y la historia personal y colectiva de los otros" (Orden ECD/65/2015, p. 6.999).

\section{Análisis del álbum}

Dado que en un álbum todo forma parte de la narrativa, vamos a analizar tanto el contenido como el continente del texto seleccionado.

Como ya se ha dicho, estudiaremos la versión independiente no traducida del inglés, aunque comparándola con la versión en español incluida en Cuentos de la periferia (Figuras 1 y 2). 
Desde la misma portada, pasando por las guardas y página del título, hallamos elementos que generan extrañeza: la tipografía, el empleo de una lengua desconocida, imágenes de plantas no familiares, un personaje antropomórfico pero no humano y de dimensiones reducidas, etc.
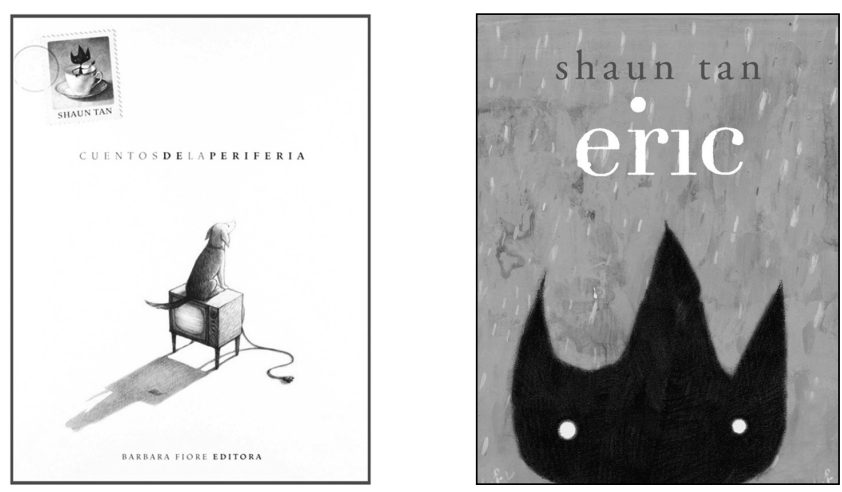

Figuras 1 y 2. Portadas de Cuentos de la periferia y de Eric

Si nos adentramos en la narración propiamente dicha, se nos plantea la situación de una familia que acoge a un estudiante extranjero de intercambio, Eric. A lo largo de todo el texto se van recreando escenas que nos hablan del desencuentro cultural y la falta de comunicación.

Durante el despliegue de la historia, el autor, Shaun Tan, va introduciendo perturbaciones que remueven las preconcepciones del público lector: el desconocimiento del verdadero nombre del estudiante, su aspecto (Figura 3), su continua recogida de objetos que molesta a la narradora, la falta de respuestas de esta ante las preguntas de Eric, la evolución del discurso desde la curiosidad al rechazo y el desconcierto, el recurso a la expresión "debe ser una cuestión cultural", etc.

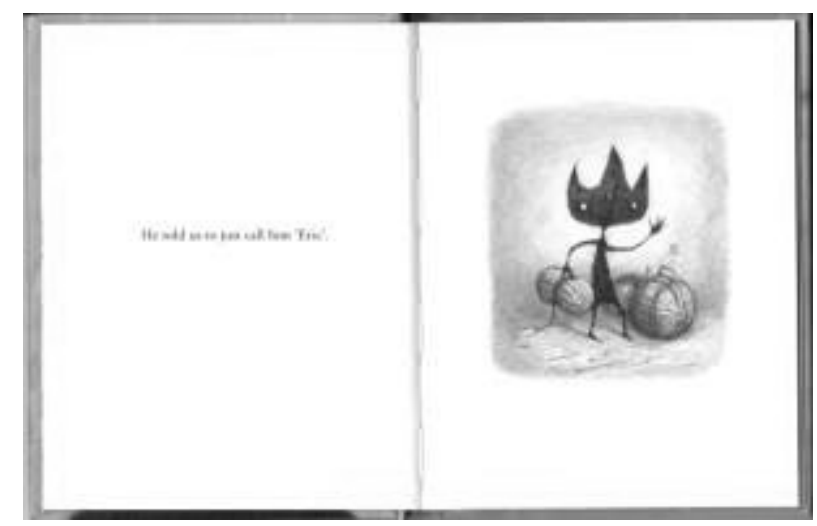

Figura 3. Presentación del personaje 
Tan nos muestra un posicionamiento de la narradora (y su familia) que evidencia un conflicto, que al final queda sin resolver (Figura 4).

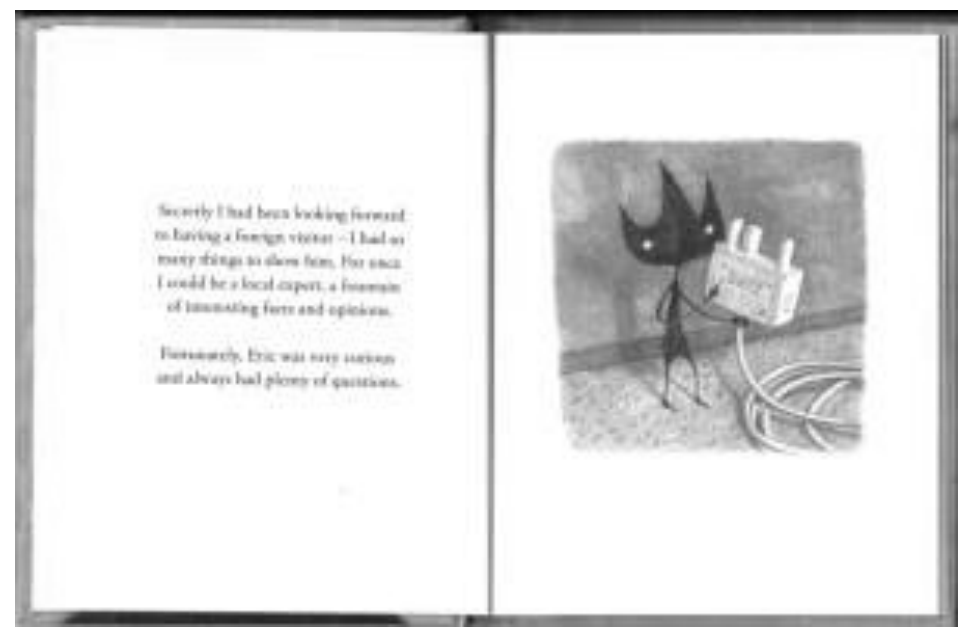

Figura 4. Posicionamiento de la narradora

Quien lee la obra pronto descubre que, a lo largo de todo el texto, y sin darse cuenta, la narradora ha ido tejiendo alrededor del protagonista la idea de alteridad. Paulatinamente lo ha convertido en "el otro" que se opone al "nosotros" familiar (identidad). Esa idea se articula en torno a varios núcleos: el otro es innombrable, no habita entre nosotros, no comparte nuestras costumbres y no pertenece a la comunidad.

El autor no cierra el planteamiento, y al concluir la historia, en el aire quedan más preguntas que respuestas. Se dirige al final al público y lo invita a mirar en la despensa. Allí, descubrimos un jardín creado por el estudiante con los objetos recogidos, y una nota de despedida dando las gracias (Figuras 5 y 6). Como colofón, solo la frase de la madre: "debe de ser una cuestión cultural".
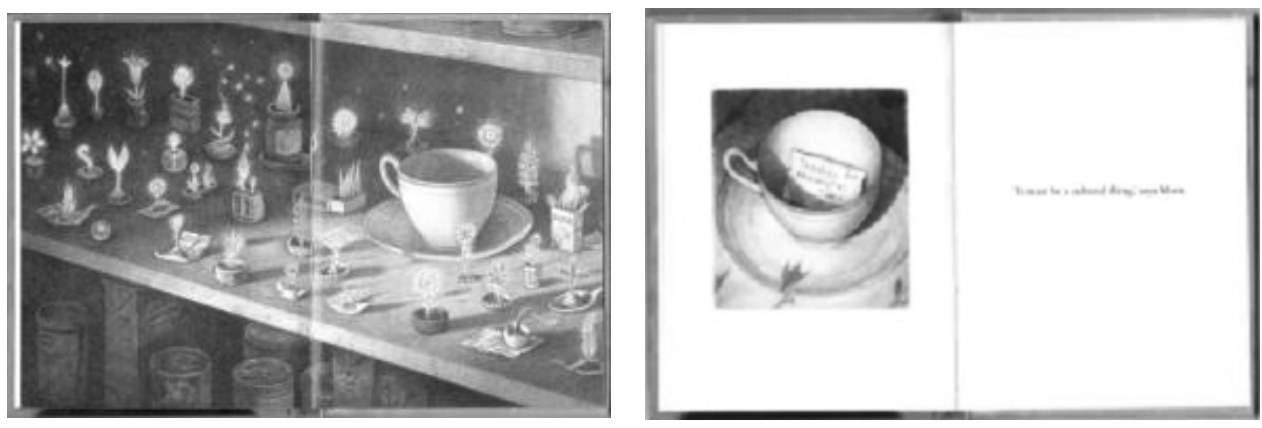

Figuras 5 y 6. Imágenes del jardín y la nota dejada por Eric 


\section{Método}

\section{Relación con el currículo}

Como ya se ha apuntado, la propuesta va dirigida al alumnado de Educación Primaria. Para llevarla a cabo se ha empleado como técnica principal el grupo de discusión. Consideramos adecuada esta elección pues, siguiendo la argumentación de Silva-Díaz (2005):

Para saber más sobre la comprensión, parece necesario observar lo que los lectores pueden expresar en conversaciones y discusiones acerca de la experiencia de lectura. Se trata de aspectos ligados a la comprensión que probablemente permanecerían ocultos o incluso no podrían desarrollarse, pues aparecen y se construyen sólo durante el intercambio (p. 94).

Como se verá en la discusión de resultados, esta decisión fue oportuna, pues el alumnado participante se expresó comparativamente mucho mejor de forma oral que como suele hacerlo de forma escrita. Incluso aquellos alumnos que se mostraban reticentes a cumplimentar el cuestionario por sus dificultades de lectoescritura, intervinieron activamente y de manera acertada en el grupo de discusión.

La propuesta planteada, por otra parte, está conectada con el currículo para la antedicha etapa, pues enlaza con aquellos elementos en él que promueven el logro de las citadas competencias sociales y cívicas. Y esto ocurre tanto para el área de Lengua y Literatura, como para la de Ciencias Sociales, dando muestra de la posibilidad de uso interdisciplinar del álbum.

Para alcanzar los objetivos pretendidos, ha sido necesario que el grupo de discusión se constituyera como foco de desestabilización, que condujera al alumnado a la incomodidad con respecto a lo que se expone en el álbum. Que lo llevara a la reflexión sobre el comportamiento de la familia y el visitante. Pues preparando a nuestros educandos para este ejercicio cognitivo tendrán la oportunidad de:

- Ponerse en el lugar del otro: al cuestionarse la actitud de la narradora.

- Aceptar las diferencias: no tratando de imponer los valores culturales y lingüísticos propios.

- Ser tolerante: comprendiendo que nuestros patrones culturales no son mejores ni peores que los de otras personas. Evitando actitudes como las de la narradora cuando expresa que el comportamiento del visitante la saca de quicio.

- Respetar los valores, las creencias, las culturas y la historia personal y colectiva de los otros: no rechazando aquello que no conocemos, o alegando que "se trata de una cuestión cultural" para no profundizar en su conocimiento.

Mediante el análisis pormenorizado y guiado de los aspectos comentados, ha resultado posible llegar igualmente a una mayor comprensión de lo que significa una ciudadanía democrática, incidiendo también en que solo a partir de la integración de todos los contextos culturales y lingüísticos que se dan en un espacio será posible la convivencia pacífica. Tal y como expone Colombo (2012, pp. 50-52), es necesario:

[...] poner en evidencia una característica de la democracia que hasta ahora había quedado de lado: el sentido de pertenencia a la comunidad. [...] Si uno forma parte de una 
comunidad, se reconoce, y reconociéndose, coopera con el bien de todos. Cuanto más amplia es la comunidad (hasta volverse planetaria), cuanto más amplio es el reconocimiento recíproco, más idóneo es el instrumento democracia para gobernar la sociedad, para que se promueva la libertad de todos, sin discriminaciones.

Porque, si queremos una sociedad plural, donde todos los contextos aporten y convivan, habremos de exponer que esta no está exenta de conflicto, pero que este es superable. Si nos remitimos a Ortuño, Miralles y Molina Puche (2012): "ese conocimiento y reconocimiento de la alteridad es pilar indispensable para la resolución de la conflictividad por cauces pacíficos" (p. 48).

\section{Alumnado participante}

Se seleccionó para tal efecto a un primer grupo de cuarto de Educación Primaria; y a un segundo compuesto por alumnado de quinto y sexto curso de la misma etapa. Tanto en el de cuarto como en el de quinto hallamos cinco niñas y un niño. El conjunto de sexto era el menos numeroso, con solo una niña y un niño (por eso se decidió unirlo al anterior). El centro en el que se llevó a cabo la propuesta es incompleto, es decir, no llega a tener una línea por nivel. El bajo número de alumnos obliga a concentrar dos cursos en un solo grupo $\left(1^{\circ}\right.$ y $2^{\circ}, 3^{\circ}$ y $4^{\circ}, 5^{\circ}$ y $\left.6^{\circ}\right)$. Este colegio se inserta en un contexto socioeconómico y cultural medio bajo. Además, la diversidad es también una nota dominante, pues hay discentes de origen magrebí, centroamericano y sudamericano, además de los provenientes de familias españolas (a su vez, de etnia gitana y no gitana). Aunque no hay graves conflictos en el centro, sí que se percibe la necesidad de incidir en el desarrollo del respeto y la aceptación de la citada diversidad. Por otra parte, en cuanto al nivel académico del alumnado, está muy influido por el contexto. Se aprecian especialmente dificultades de comprensión lectora. No obstante, ambos grupos han tenido contacto previo con los álbumes ilustrados, y han mostrado un mayor entendimiento de estos que de otro tipo de textos.

\section{Procedimiento}

La intervención se desarrolló en dos sesiones.

Primera sesión: se comunica al alumnado que se va a dar comienzo a una actividad que gira en torno a la lectura de un libro. La tarea inicial consiste en, tras la lectura de la página de apertura del álbum (donde se nos cuenta quién es Eric y el porqué de ese nombre), dibujar al personaje protagonista y a quien está narrando. No se les enseña el libro, solo conocen el título y este primer párrafo introductorio. Se anticipa que después del dibujo se leerá la obra.

Una vez finalizados los dibujos empieza la lectura por parte del docente. Al tiempo que lee, se va proyectando en la pizarra digital el texto escaneado (la versión inglesa). Se muestra igualmente la portada, contraportada y guardas. Se van señalando aquellos aspectos relevantes para la comprensión de la historia, así como se realizan preguntas que vayan guiando la reflexión (cuál es el nombre real de Eric, qué significan algunas frases, qué se podría hacer para mejorar la comunicación, interrogantes sobre lo que ocurrirá a continuación, expectativas de la narradora, etc.). 
Al terminar la lectura hay un momento para la reflexión final y comentarios por parte del alumnado, recopilando ideas que se hayan ido esbozando durante la narración.

Segunda sesión: una vez cerrada la fase de grupo de discusión, se distribuye a los discentes un cuestionario de diez ítems, relativos a aspectos del texto leído.

Los ocho primeros ítems plantean situaciones del texto o hipotéticas y una pregunta ligada a ellas. Hay dos opciones de respuesta, consistentes en afirmaciones cerradas. En el noveno ítem se propone la búsqueda de términos en el texto, y el décimo es una pregunta abierta.

Para la redacción de estos ítems se han considerado los objetivos iniciales, así como las posibilidades del texto para su logro. Procederemos a realizar una descripción más detallada de los puntos planteados:

Remarcamos un primer bloque, de la cuestión uno a la tres, centrado en el modo en que se afronta la diversidad lingüística. Al pretender que el alumnado sea capaz de ponerse en el lugar del otro, las dos opciones de respuesta fuerzan su posicionamiento, además de guiarle en el cuestionamiento del comportamiento de la familia de acogida. Los estudiantes han de decidir si la sociedad que acoge debe realizar un esfuerzo comunicativo, o si debe, por contra, darse un proceso de aculturación.

El segundo bloque se inicia en la pregunta cuatro y finaliza en la seis. En él se aborda la cuestión del encuentro de los dos contextos culturales, y los sentimientos e ideas que lleva consigo el desajuste entre la expectativa y la realidad. La idealización del encuentro y la aceptación de la diversidad cultural son los ejes que articulan este bloque. Por otra parte, se insiste en el desarrollo del pensamiento crítico, al plantear cuestiones que en el texto se han obviado (como la posibilidad de enseñar a o ser enseñado por).

El tercer bloque, que engloba las preguntas siete y ocho, gira en torno al fallo en la comunicación intercultural, y, a su vez, profundiza en la comprensión de la interacción del lenguaje visual y verbal propia del álbum.

Enlazando un poco con los aspectos literarios de este último bloque surge la novena cuestión, en la que el alumnado ha de encontrar en la parte verbal las expresiones de los sentimientos que se manifiestan en la familia de acogida. Esta búsqueda ayuda a sintetizar y ver de forma más clara el conflicto no resuelto que ha supuesto el encuentro intercultural. Por otra parte, contribuye a que los educandos puedan hallar reflejada en esas palabras o grupos de palabras la expresión de su propio desconcierto frente al texto. Esto procura el movimiento oscilante de ida y vuelta (identidad/ alteridad).

Por último, el ítem diez propone una reflexión individual sobre aquello que Eric deja en la despensa. Sirve para diversos fines: por un lado pone punto final recopilando ideas previas aparecidas durante la lectura (para qué era lo que recogía el personaje, el sentido de sus preguntas, etc.), por lo que incide en la comprensión lectora. Por otro lado, proporciona al alumnado la oportunidad de desarrollar su propio discurso crítico, valorando la acción del estudiante de intercambio.

Es preciso comentar que para la redacción de estos ítems se ha tenido en cuenta igualmente el nivel lectoescritor del alumnado participante, procurando adaptar al máximo el vocabulario. Para facilitar la tarea se han leído en vOz alta todos los ítems y se han atendido dudas durante su realización. 
Otra cuestión que se ha considerado para la elaboración de este cuestionario era la existencia de otros en los estudios previos. Así, han servido de ejemplo los propuestos por Encabo, López y Jerez (2012), y Santisteban y Pagès (2009), dirigido a Educación Secundaria. Sin embargo, se han producido cambios sustanciales con respecto a ellos, al tratarse de otra etapa y centrarnos en el texto leído.

\section{Resultados}

Al analizar las producciones del alumnado observamos que tanto Eric como la narradora son representados como personas de raza blanca, jóvenes, y mayoritariamente de género masculino. De catorce participantes solo cuatro (todas alumnas) consideran que pueda tratarse de una narradora. En el caso de Eric solo una niña cree que pueda ser de género femenino. Otra, en cambio, le atribuye cuerpo humano y cabeza de perro (no explica el porqué). Dos niños representan al estudiante con gafas, al parecer siguiendo el estereotipo.

En cuanto al grupo de discusión desarrollado durante la lectura, el alumnado se muestra desconcertado al ver la imagen de Eric, preguntan qué o quién es (plantean posibilidades: una llama, una hoja, un tenedor...). Descubren que no pueden saber su nombre porque el texto no lo dice, lo que les crea aún más inquietud. Pese a ello, señalan que el personaje es educado y se porta bien con la familia. Al principio creen que no habla, y que es eso lo que provoca que la narradora no sepa qué siente o piensa. También manifiestan su asombro ante el tamaño del estudiante, apuntan que lo han ilustrado así para que quienes lo lean se rían, "para meterse en el papel"; o "para que se vean las otras cosas". Relacionan el jardín de la doble página final con los objetos que ha ido recogiendo el personaje y con el dibujo de las semillas de las guardas, mostrando que han seguido y comprendido la narración. Es preciso explicarles qué significa el término "hospitalidad", pues lo desconocen.

Al finalizar la lectura el alumnado se sigue preguntando qué es Eric.

En la conversación desarrollada sobre el nombre, se observa que los discentes no conectan el nombre propio con la idea de identidad, y les parece factible el cambio.

Eric les parece "inesperado", al preguntarles por qué y cuál era su expectativa, dicen que: "un estudiante de toda la vida". Proponen que la razón de la narradora para querer tener un extranjero era la de enseñarle cosas, lo que da pie a la pregunta de si aquel le enseña algo a ella. Esta pregunta les genera incertidumbre y responden que no, con aire dubitativo. Una alumna alega que sí, las cosas que se encuentra.

Concluyen esta parte expresando su malestar por no saber quién o qué es Eric, y por desconocer su nombre real. Acostumbrados a las narrativas cerradas, la apertura del texto les desestabiliza, pero hay que recordar que ese era uno de los objetivos de la propuesta.

Cuestionados acerca de la comunicación entre la narradora, así como su familia, y Eric, argumentan que no se comunican bien, y que puede deberse a varias razones: no hablan con el estudiante, o este se pasa el día estudiando y recogiendo cosas del suelo. El docente les lee de nuevo ejemplos del texto de esta falta de comunicación. Como solución el alumnado propone que hablen, y que le pregunten al estudiante qué es aquello que le gusta. 
Al exponerles la pregunta de qué cosas podría enseñar Eric a la familia de acogida, responden "amabilidad", "alegría", "que hay que ser amable". Aunque apuntan que el estudiante era un poco raro.

Por otro lado, se les interroga acerca de la incomodidad y enfado de la narradora, y comentan que puede deberse a "porque lo quiere aprender por sí solo", refiriéndose a Eric. Un alumno dice que le molesta porque "le tenía odio", a lo que otro contraargumenta que no es posible porque "era muy bueno". Observamos que el alumnado, a pesar del desconcierto, tiene una visión positiva del estudiante, y ha llegado a empatizar con él.

Para terminar se les pregunta sobre lo que saben de Eric y su cultura. Indican que le gustan las plantas y las colecciona. Desarrollan entonces su propia teoría sobre el motivo del estudiante para el viaje: ha ido a estudiar las plantas, pero no se lo puede decir a la narradora porque no sabe su idioma. Califican el jardín de "tesoro". Dicen que Eric se porta bien o muy bien, educado, aunque un poco raro (porque no habla, no dice nada, solo coge cosas del suelo). Da la sensación de que se ha producido el quiebre entre identidad/alteridad, pues si bien al principio representaban a la narradora englobada en el "nosotros", al final dudan de su comportamiento y se posicionan a favor del estudiante, que a pesar de sus rarezas es educado y deja un regalo. Así, alegan que la narradora se porta "regular", porque "le pide muchas cosas a Eric, y como Eric no quiere..."

En lo que respecta a los cuestionarios, resumiremos los resultados, bloque por bloque:

Bloque uno, relativo a la diversidad lingüística: la mayoría del alumnado considera adecuado el cambio en el nombre del estudiante, coincidiendo con lo expresado de forma oral. Tanto cuando se refieren a Eric como a sí mismos no creen que deba implicar el sentirse mal o algo negativo.

Bloque dos, relativo al encuentro de los dos contextos culturales y los sentimientos que lleva parejos: el alumnado se posiciona a favor de la aceptación de la diversidad de culturas, la no imposición de patrones culturales y el respeto. Destacan, empero, las respuestas al sexto ítem, que pretendía incidir en el pensamiento crítico. En ellas parecen surgir algunas discordancias en el grupo, pues si bien nueve han contemplado la primera opción ("es normal, ella tenía que enseñarle al estudiante"), cinco se inclinan por que él también podría enseñar algo a ella.

Tercer bloque, relativo a la falta de comunicación intercultural: se aprecia un claro posicionamiento de parte del estudiante, Eric, que concuerda con lo expresado de forma oral. La mayoría de los discentes cree que la narradora debería haber realizado un mayor esfuerzo para establecer la comunicación.

Noveno ítem, relativo a las manifestaciones de sentimientos: en general señalan que la narradora y su familia se sentían mal, con sensación de extrañeza e inutilidad. Rescatan del texto las expresiones "sacaba de quicio" o "ninguno de nosotros pudo evitar sentirse desconcertado". Incluyen otras expresiones que aluden a la falta de comunicación y la incomodidad que provoca. En otro orden de cosas, presentan conclusiones propias como que se sentían tristes por perder a un miembro de la familia, o que se sentían bien porque Eric era muy educado. Posiblemente esta sea la pregunta que representó una mayor dificultad para el alumnado, dado que le costaba encontrar en el texto lo que se le solicitaba (dispusieron de la versión en español para ello). 
Décimo punto, relativo al jardín que Eric deja: aunque las respuestas no son demasiado elaboradas, en su mayoría valoran positivamente lo mostrado, añadiendo que es muy bonito, a la vez que un gesto educado y amable. Les parece una buena despedida porque deja algo de recuerdo.

\section{Discusión}

Una vez conocidos los resultados, es momento de extraer conclusiones, y para ello nos remitiremos a los objetivos iniciales:

- Avanzar hacia el desarrollo de principios propios de una ciudadanía democrática (tolerancia, aceptación de la diversidad, diálogo como forma de resolución de conflictos, etc.) por parte del alumnado de Educación Primaria. En este sentido, creemos que la lectura del texto ha procurado este avance, dado que el alumnado ha valorado de forma positiva la diversidad, y ha sido capaz de ponerse en el lugar del otro, deshaciendo la otredad tejida por la narradora en la obra.

- Desestabilizar los estereotipos y esquemas previos del alumnado con respecto a la diversidad y al par identidad/alteridad. El término "inesperado" y las continuas preguntas acerca de Eric dan muestra de la desestabilización de las ideas previas. Se ha producido además un doble desajuste: con la propia estructura narrativa (ambigua, sin cierres ni adaptación a las convenciones) y con la narración en sí. El alumnado se ha sentido desconcertado, pues si bien Eric es "raro", su comportamiento lo acerca y provoca la empatía.

- Iniciar al alumnado en el desarrollo del pensamiento crítico y la adopción de puntos de vista alternativos. Hemos percibido durante la lectura y con posterioridad a ella, en el cuestionario, un cambio en el punto de vista adoptado, desplazándose poco a poco hacia la posición del estudiante. El alumnado ha sido capaz de contemplar la posibilidad de que "el otro" enseñe, o de que haya preguntas que no sigan el esquema preestablecido. Aunque, sobre todo, lo más destacable ha sido el surgimiento de la duda, el cuestionamiento de lo esperado/esperable.

- Provocar la reflexión de los alumnos sobre la comunicación intercultural y las consecuencias de su ausencia. Creemos que este objetivo se ha logrado en gran parte, ya que el alumnado ha examinado tanto el comportamiento de Eric como el de la narradora y su familia, descubriendo que la comunicación es un camino de ida y vuelta que precisa de la voluntad de quienes en ella se implican. Ha reconocido el conflicto presente en el texto y su origen en la falta de comunicación, identificando la necesidad de su mejora para solventarlo.

- Aproximar a los discentes al género álbum y sus particularidades (textos abiertos, presencia de dos tipos de narración, verbal y visual, interconectados, ambigüedades, etc.). Aunque el alumnado ya había tenido contacto con el género, no lo había hecho con obras con un carácter postmoderno tan marcado. Sin embargo, ha respondido adecuadamente, interactuando con el texto y participando de la coautoría. Se han comprometido con la narración, rellenando las "ausencias" del autor con su propia reflexión ("presencia"). Han 
sabido conectar las dos narrativas, y seguir el hilo argumental a pesar de las ambigüedades. Y esto ha ocurrido, además, o incluso de forma más señalada, en aquellos estudiantes que manifestaban mayores dificultades de lectoescritura y comprensión lectora. El desconcierto que provocó en ellos la indeterminación de la obra no se ha constituido en obstáculo para su recepción.

Tras la revisión del logro de objetivos de manera pormenorizada, recapitulemos lo expuesto hasta ahora.

Una vez realizado el análisis del álbum seleccionado, creíamos que era posible considerar que la reflexión por parte del alumnado sobre el texto propuesto podía dar lugar al cuestionamiento de los estereotipos, ideas previas y prejuicios acerca de la validez de ciertos patrones culturales. También podía llevar a poner en quiebra las ideas sobre la supremacía de unas culturas sobre otras, así como podía contribuir a la adopción de puntos de vista ajenos al propio. Contemplando, a propósito de esta historia, tanto la diversidad lingüística como cultural.

Esta reflexión sería posible gracias a los espacios de ambigüedad que había dejado el autor del álbum, así como al desconcierto que provocaría el desmantelamiento de los esquemas de pensamiento acerca de "nosotros" y los "otros".

Todo esto, que se planteaba en un principio como una premisa, se ha visto materializado al concretar la propuesta con dos grupos de alumnos de Educación Primaria. Tal y como se ha visto en los resultados, la incertidumbre que rodeaba al texto ha hecho posible que el alumnado comenzase a interrogarse acerca del diálogo intercultural. La ruptura de los estereotipos y las expectativas ha conducido a cuestionar el mundo conocido, y a poner sobre la mesa que la diversidad cultural requiere ser respetada y aceptada, y que para ello, como paso previo, ha de darse la comunicación. Quizás el aspecto más reseñable es la transición que se ha observado en el alumnado desde la extrañeza inicial (Eric era "el otro") hasta la empatía última (el estudiante tiene algo que ofrecer, pero el fallo en la comunicación impide la comprensión). También es destacable el modo en que los discentes se han enfrentado a la actitud de la anfitriona y su familia, Ilegando a la conclusión de que su relación con el estudiante se apoyaba más en ideas prefijadas, que en un deseo de profundizar en su conocimiento.

A pesar de que se temía que las dificultades de comprensión lectora pudiesen suponer una interferencia en la asimilación de la obra, se ha tenido constancia de que no ha sido así. Además de los instrumentos citados, una semana después de leído el texto, se ha preguntado por él, y los estudiantes seguían siendo capaces de estructurar un discurso coherente y argumentado exponiendo sus pensamientos con claridad, sin desviarse de lo manifestado durante y tras la lectura.

Por otra parte, si nos centramos en el currículo, vemos que con esta propuesta el grupo-clase puede avanzar en la consecución de los elementos vinculados a los objetivos de este estudio, tanto para el área de Lengua y Literatura, como para la de Ciencias Sociales. Y, de un modo más amplio, también hace posible la progresión en la adquisición de las competencias sociales y cívicas.

Es evidente que el desarrollo de una ciudadanía democrática precisa de un trabajo continuado en el tiempo, mas la utilización de este tipo de álbumes creemos que 
puede tenerse como herramienta útil para contribuir a tal desarrollo, tal y como se ha observado en la revisión de los objetivos. Además, dicha revisión nos ha permitido corroborar los resultados de otras investigaciones previas, como la citada de Encabo, López y Jerez, donde concluyen que "la literatura infantil es un excelente medio para promover la educación intercultural" (2012, p. 424). Algo similar hallamos en las conclusiones de Cotton y Daly (2014), cuando afirman que todos los títulos seleccionados en su estudio permiten el despliegue de la conciencia intercultural. También se ajustan los resultados de esta propuesta a lo manifestado por $\mathrm{O}^{\prime}$ Neil en su trabajo: "These texts can provide an opportunity for students to see both themselves and others, explore constraints and underpinnings of social expectations, and perhaps even imagine a different way of being" (2010, p. 51).

Para reforzar lo dicho y a modo de cierre, no está de más recordar aquí nuevamente el porqué el uso de un recurso literario es útil para alcanzar los fines deseados relativos a ciudadanía, recurriendo para ello a las palabras de Manning (2003, citado en Johnston y Shariff, 2013, p. 44):

Reading is an interpretative gesture always to come that challenges my subjectivityin-process ... Reading can also be formulated as a proposal for an encounter with the other. The text is the other to whom I turn not for comprehension, but for the challenge of exposing my own difference.

\section{REFERENCIAS BIBLIOGRÁFICAS}

Bainbridge, J. y Beverly, B. (2013). Picture books and Pedagogy: From Possibilities to Practice. En I. Johnston y J. Bainbridge (Eds.), Reading Diversity through Canadian Picture Books. Preservice Teachers Explore Issues of Identity, Ideology, and Pedagogy (pp. 18-40). Canadá: University of Toronto Press.

Colombo, G. (2012). Democracia. Buenos Aires: Adriana Hidalgo Editora.

Colomer, T. (2010). Álbumes ilustrados y cambio de valores en el cambio de siglo. En T. Colomer, B. Kümmerling-Meibauer y M. C. Silva-Díaz (Coords.), Cruce de miradas: nuevas aproximaciones al libro-álbum (pp. 58-73). Barcelona: Ekaré.

Cotton, P. (2000). Picture Books Sans Frontières. Staffordshire: Trentham Books.

Cotton, P. y Daly, N. (2014). Visualising Cultures: The "European Picture Book Collection" Moves "Down Under". Children's Literature in Education 46(1), 88-106. http://doi. org/10.1007/s10583-014-9228-9.

Encabo, E., López, A. y Jerez, I. (2012). Un estudio sobre el uso de álbumes ilustrados en Educación Primaria para la mejora de la competencia intercultural. Una perspectiva europea. Revista de educación, 358, 406-425.

Johnston, I. y Bainbridge, J. (Eds.) (2013). Reading Diversity through Canadian Picture Books. Preservice Teachers Explore Issues of Identity, Ideology, and Pedagogy. Canadá: University of Toronto Press.

Johnston. I. y Shariff, F. (2013). Who Does This Text Think I Am? Exploring Questions of Subjectivity through Diverse Picture Books. En I. Johnston y J. Bainbridge (Eds.), Reading Diversity through Canadian Picture Books. Preservice Teachers Explore Issues of Identity, Ideology, and Pedagogy (pp. 41-55). Canadá: University of Toronto Press. 
Lebedeva, M. (2013). A play of signifiers: absence and presence in the picturebooks of Shaun Tan. (Tesis de Máster, University of Stellenbosch). Recuperado de http:// hdl.handle.net/10019.1/79950.

O'Neil, K. (2010). Once Upon Today: Teaching for Social Justice with Postmodern Picturebooks. Children's Literature in Education, 41, 40-51. http://doi.org/10.1007/ s10583-009-9097-9 40-51.

Orden ECD/65/2015, de 21 de enero, por la que se describen las relaciones entre las competencias, los contenidos y los criterios de evaluación de la educación primaria, la educación secundaria obligatoria y el bachillerato. Boletín Oficial del Estado, 25, 29 de enero de 2015, pp. 6986-7003.

Ortuño, J., Miralles, P. y Molina Puche, S. (2012). Ciencias sociales y su didáctica. Murcia: Diego Marín.

Santisteban, A. (2004). Formación de la ciudadanía y educación política. En M. I. Vera y D. Pérez (Coord.), Formación de la ciudadanía: las TICs y los nuevos problemas. Alicante: Asociación Universitaria de Profesores de Didáctica de las Ciencias Sociales.

Santisteban, A. y Pagès, J. (2009). Una propuesta conceptual para la investigación en educación para la ciudadanía. Revista Educación y Pedagogía, 21(53), 15-31.

Silva-Díaz, M. C. (2005). Libros que enseñan a leer: álbumes metaficcionales y conocimiento literario. (Tesis doctoral). Recuperado de http://hdl.handle. net/10803/4667.

Tan, S. (2008). Cuentos de la periferia. Granada: Barbara Fiore Editora.

Tan, S. (2010). Eric. Surrey: Templar Publishing. 